\title{
Avicenna Journal of Medicine: Reviving fading legacy
}

Marking another milestone, the Syrian American Medical Society (SAMS) is honored to present the Avicenna Journal of Medicine (AJM) to the Arab and Syrian medical society with much optimism to be a leader in enhancing healthcare and promoting biomedical research among Syrian and Arab physicians.

Medieval scientists established a solid basis for medical practice and education emphasizing the important role of medical publishing and documentation of clinical observations and experiments. Of them is IbnSina (Avicenna, 981-1037 CE), a well-known scholar whose outstanding contribution to the medical literature is well recognized and still studied and taught in medical schools worldwide. His book "The Canon" led the field of medicine as the authoritative, systematic text-book for over five centuries throughout the Renaissance. Hence, this journal is honored to hold his name looking forward to revive his legacy of science, research, and medical publishing.

At present, practicing evidence-based medicine in the Arab world is challenged by the lack of resources and infrastructure to produce basic biomedical research and the paucity of locally generated clinical studies. This is, in part, related to lack of locally operated journals and the tendency to publish in internationally recognized journals, which are often inaccessible by practicing physicians in the country of data origin.

\begin{tabular}{|l|l|}
\hline \multicolumn{2}{|c|}{ Access this article online } \\
\hline Quick Response Code: & Website: \\
\hline & www.avicennajmed.com \\
\cline { 2 - 2 } & \\
\hline
\end{tabular}

Establishing the Avicenna journal of medicine, an open access journal, was to facilitate publishing and accessing biomedical studies and literature by international, Arab, and Syrian researchers and academicians while focusing on locally produced basic and clinical studies. The quarterly journal has a free electronic submission system and allows free online worldwide access to its contents.

The editorial board, represented by professionals and academicians from various medical specialties, is committed to maintain high standards in reporting and scientific conduct by a thorough peer review and editorial process. The journal will publish original studies, literature reviews, editorials, and case reports from various medical specialties covering a broad spectrum of clinical and biomedical topics. The expanding list of scientific reviewers includes highly qualified professionals who enrich the content of the journal with their experience.

Our vision is to be a leading journal in the field of medicine and participate in improving healthcare in the Arab world, particularly in Syria, and promote research and editorial skills among the coming generations of medical professionals.

As we present the first issue of the journal to our readers, we are grateful for those who submitted their work and looking forward to future scientific contributions by all colleagues.

Mohammad Arabi, Bassel Atassi ${ }^{1}$, Haitham Arabi ${ }^{2}$ Department of Radiology, University of Michigan, Ann Arbor, ${ }^{1}$ Departments of Hematology/Oncology and ${ }^{2}$ Pathology, Wayne State University, Detroit, MI, USA E-mail:marabi@med.umich.edu

Cite this article as: Arabi M, Atassi $\mathrm{B}$, Arabi H. Avicenna Journal of Medicine: Reviving fading legacy. Avicenna J Med 2011;1:1.

Announcement

\section{“QUICK RESPONSE CODE” LINK FOR FULL TEXT ARTICLES}

The journal issue has a unique new feature for reaching to the journal's website without typing a single letter. Each article on its first page has a "Quick Response Code". Using any mobile or other hand-held device with camera and GPRS/other internet source, one can reach to the full text of that particular article on the journal's website. Start a QR-code reading software (see list of free applications from http://tinyurl.com/yzlh2tc) and point the camera to the QR-code printed in the journal. It will automatically take you to the HTML full text of that article. One can also use a desktop or laptop with web camera for similar functionality. See http://tinyurl.com/2bw7fn3 or http://tinyurl.com/3ysr3me for the free applications. 